Working Papers on Environmental Sciences

\title{
Power capacity: A key element in sustainability assessment
}

\author{
François Diaz-Maurin ${ }^{(1)}$
}

Affiliations:

${ }^{1}$ Institut de Ciencia i Tecnologia Ambientals (ICTA), Universitat Autònoma de Barcelona (UAB), Bellaterra 08193, Barcelona, Spain.

Contact: François Diaz Maurin <Francois.Diaz@uab.cat>

Date: 09-11-2015 
Refer to as:

F. Diaz-Maurin. Power capacity: A key element in sustainability assessment. Working Papers on Environmental Sciences, Institut de Ciència i Tecnologia Ambientals (ICTA), Universitat Autònoma de Barcelona, 9 November 2015.

Institut de Ciència i Tecnologia Ambientals (ICTA)

Edifici ICTA-ICP - Campus de Bellaterra

08193 Cerdanyola del Vallès - Barcelona, Spain

Tel.:(+34) 935868777

icta@uab.cat·www.uab.cat/icta

Tel: (+34) 935812974

http://uab.cat/icta

icta@uab.cat 


\section{Power capacity: A key element in sustainability assessment}

François Diaz-Maurin $^{(\mathrm{a}) \text { * }^{*}}$

(a) Institut de Ciencia i Tecnologia Ambientals (ICTA), Universitat Autònoma de Barcelona (UAB), Bellaterra 08193, Barcelona, Spain.

*: (Corresponding author) Tel. +34 9358686 36. E-mail address: Francois.Diaz@uab.cat

\section{Abstract}

In the field of complex energetics, human societies to survive follow the same 'maximum power principle' as other living systems. In this view, human societies developed because they have been able to increase 'their capacity to convert energy at a given time rate' rather than simply increase 'their level of energy consumption'. This was translated into an increase of the level of power capacity in human societies so far. Yet, one can expect that the level of power capacity will be altered in light of the unavoidable progressive depletion of fossil energy resources. The systemic study of power capacity in sustainability assessment is therefore essential for facing the external constraints ahead.

This paper seeks to clarify the concept of power capacity in sustainability assessment. It provides explicit methods of assessment for the different types of power capacity used by human societies. Power capacity refers to the converters transforming energy flows at a given time rate. Dealing with societal transitions therefore requires being able to characterize properly those converters in addition to the study of energy flows. However, this requires extending the timescale typically considered in conventional energy analysis which entails several epistemological problems over sustainability assessment.

Keywords: Power level; Theoretical ecology; Complex energetics; Sustainability assessment; Energy transition; Societal metabolism; MuSIASEM

Abbreviations: $A G$, agriculture and fisheries; $B M$, building and manufacturing; $C B E$, converter-based evaluation; $\mathrm{CL}$, capacity load; $\mathrm{EC}$, energy carrier; $\mathrm{El}$, energy input; $\mathrm{ELEC}$, electricity (energy carrier); EM, energy and mining; EO, energy output; ET, energy throughput; EU, end uses; FBA, flow-based approximation; FUELS, fuel products (energy carrier); GER, gross energy requirement; GSEC, gross supply of energy carrier; HA, human activity; HEAT, process heat (energy carrier); $\mathrm{HH}$, households; IPCD, input of power capacity dissipative; IPCH, input of power capacity hypercyclic; LT, lifetime; LU, land use; M\&M, minerals and materials; MR, metabolic rate; NSEC, net supply of energy carrier; OL, operating load; OPCH, output of power capacity hypercyclic; PC, installed power capacity (dissipative or hypercyclic); $\mathrm{PCD}$, power capacity dissipative; $\mathrm{PCH}$, power capacity hypercyclic; PES, primary energy sources; SG, services and government; UF, utilization factor; WS, whole society 


\section{Introduction}

Conventional assessment of the sustainability of human societies deals only with one scale at a time. It typically adopts the timescale of one year so as to consider the average annual consumption of energy and other natural resources. However, this choice over a fixed time horizon makes such analyses unable to properly address societal transitions in quantitative terms.

The study of the energetics involved in societal transitions requires considering a much larger timescale. When doing so it becomes possible to move from a discussion over exosomatic energy flows to a discussion over exosomatic energetic funds. Exosomatic energetic funds are the capital funds (facilities and appliances) able to convert energy flows at a given power level either on the demand or on the supply side. The study of power level (the time rate at which energy flows are converted) and of the associated power capacity (the energy converters and energy supply systems) is one of the missing pieces in sustainability assessment (Giampietro et al. 2012). Power density (the rate of energy flows per unit of area) also is an important measure that is still largely overlooked in sustainability assessment (Smil 2015).

This paper endorses the claim that the development of human societies followed the same 'maximum power principle' as observed in ecosystems. That is, human societies developed because they have been able to increase 'their capacity to convert energy at a given time rate' rather than simply increase 'their level of energy consumption'. This was translated into an increase in power capacity which corresponds to the converters consuming and supply systems generating energy flows.

To understand the importance of power capacity processing energy flows for the sustainability of human societies, we can use the metaphor of 'the bucket and the well'. Let's imagine that a family requires collecting freshwater from a well every day for drinking. The quality of their supply of drinking water does not depend only on the quality of the water nor only on the quantity of the water stored in the well. Besides, the quality of the supply also depends on the characteristics of the bucket used to collect the freshwater. For instance, if the bucket has a hole at the bottom it will carry less water for every lifting-up cycle. And if the hole becomes too large, the bucket will no longer perform its function at the expected rate and will probably have to be repaired or replaced unless the family will remain thirsty sitting on top of a stock of freshwater...

Similarly, human societies require power capacity-coming from human labor, animal labor or machines-dissipating energy in order to be able to perform its functions.

Power capacity is a key production factor of the socio-economic process which can act as a limiting factor for its reproduction. In doing so, the paper focuses on the power capacity required to dissipate exosomatic energy, that are flows under human control but outside human (and animal) bodies. In human societies, exosomatic energy flows correspond to the 
various forms of energy processed by the energy sector, including primary energy sources and energy carriers.

This paper proposes an accounting framework that seeks to clarify the concept of power capacity and provide explicit methods of assessment. In doing so, it aims at making a case for the systemic inclusion of power capacity in the sustainability assessment of human societies.

The paper starts in Section 2 with a discussion about the different possible timescales at which energy conversions can be perceived. The meta timescale of analysis implies that any use of energetic analysis for dealing with societal transitions requires being able to characterize properly the energy converters and energy supply systems.

In Section 3, the paper defines the concept of power capacity, makes the distinction between the different types of power capacity and proposes a taxonomy as well as assessment methods for its formalization. Those assessment methods of power capacity make it possible to describe energy converters and energy supply systems as production factors of the socio-economic process which can then be integrated in energetic analysis.

Section 4 provides some examples of assessments of power capacity using the methods introduced in Section 3. It then makes a comparison of the assessments illustrating some characteristics specific of power capacity.

The paper concludes in Section 5 by identifying some empirical efforts further needed to achieve the systemic inclusion of power capacity in energetic analysis and sustainability assessment more in general.

\section{The different timescales of energy conversions}

The interdisciplinary field of 'energetics of complex systems' deals with the systemic analysis of energy transformations describing the interaction between human societies and the environment (Diaz-Maurin and Giampietro 2013a). In this field human societies are considered as complex living systems self-organized around metabolic patterns (Giampietro et al. 2011). This is Zipf (1941) who started to compare the organizational pattern of societies to the metabolism of 'bio-social organisms'. He identified the existence of a pattern of self-organization over power laws in socio-economic systems. Those laws and principles were originally developed in theoretical ecology (Odum 1971, 1983, 1996).

The metabolic perception of human societies entails the acknowledgment of the existence of hierarchical relations and interdependences across scales in the description of their 'functional' processes like the one characterizing living systems. A quantitative analysis of the energetics of human societies therefore requires dealing simultaneously with multiple scales (Diaz-Maurin and Giampietro 2013a). 
The unavoidable existence of multiple non-equivalent perceptions and representations in energetics implies that, when dealing with hierarchically organized adaptive systems, it is virtually impossible to have 'a correct assessment' of energy conversions. Rather the analyst has to address a set of relevant characteristics of the processes of transformations that are level and scale dependent in order to be able to decide about the relevance of the chosen perceptions and representations. This implies that the analyst should acknowledge the coexistence of a variety of non-equivalent perceptions and representations of energy transformations across scales and take responsibility for the choice of adopting only a limited (set of) scale(s) at a time. Energy conversions controlled by human societies can also be perceived at various space scales, which entail various possible quantitative representations (see e.g., Giampietro et al. 2012, Diaz-Maurin and Giampietro 2013a, Giampietro and Diaz-Maurin 2014). This section focuses on the various time scales at which energy conversions can be perceived. This requires going back to the concept of 'power level'.

The power level or metabolic rate corresponds to the ability of living systems to metabolize energy flows in time (Diaz-Maurin and Giampietro 2013a). It is essential for expressing their functions and reproducing themselves. The quest for an increased metabolic rate is at the core of the very definition of life where "in the struggle for existence, the advantage must go to those organisms whose energy capturing devices are most efficient in directing available energies into channels favorable to the preservation of the species" (Lotka 1922: 147). Building on Lotka's (1922) maximum energy flux principle, H.T. Odum proposed a general maximum power principle for the development of ecological systems which consists in the 'survival of the fittest' by means of "the persistence of those forms which can command the greatest useful energy per unit time (power output)" (Odum and Pinkerton 1955: 332).

The introduction of the maximum power principle into the analysis of the energetics of living systems such as socio-economic systems brings the time dimension back into the scientific discourse (Diaz-Maurin and Giampietro 2013a). For some, including H.T. Odum, the field of energetics should even be based on the study of power rather than on the study of energyto the extent that it has been proposed as the fourth thermodynamic law (Odum 1963, 1994). This is the rationale behind the approach for the systemic study of power capacity proposed in this paper.

Previous work has been done already in dealing with the various timescales at which human societies metabolize energy flows (Giampietro et al. 2012) as well as how they metabolize water flows against the structural and functional stability of ecological funds (Madrid et al. 2013). This section elaborates further on generalizing those distinct timescales of analysis and on discussing their implications for the analysis of the energetics of human societies. It should be mentioned that this study refers only to exosomatic energy flows that are the energy conversions under human control but outside human body. In this view human labor is therefore not accounted for as an endosomatic energy flow (inside human body) but 
rather as a production factor of the socio-economic process referring to the use of human time (for an in-depth discussion over the problems of accounting human labor in energy analysis, see Giampietro et al. 1993).

Fig. 1 summarizes the four timescales useful to describe the energy conversions of human societies.

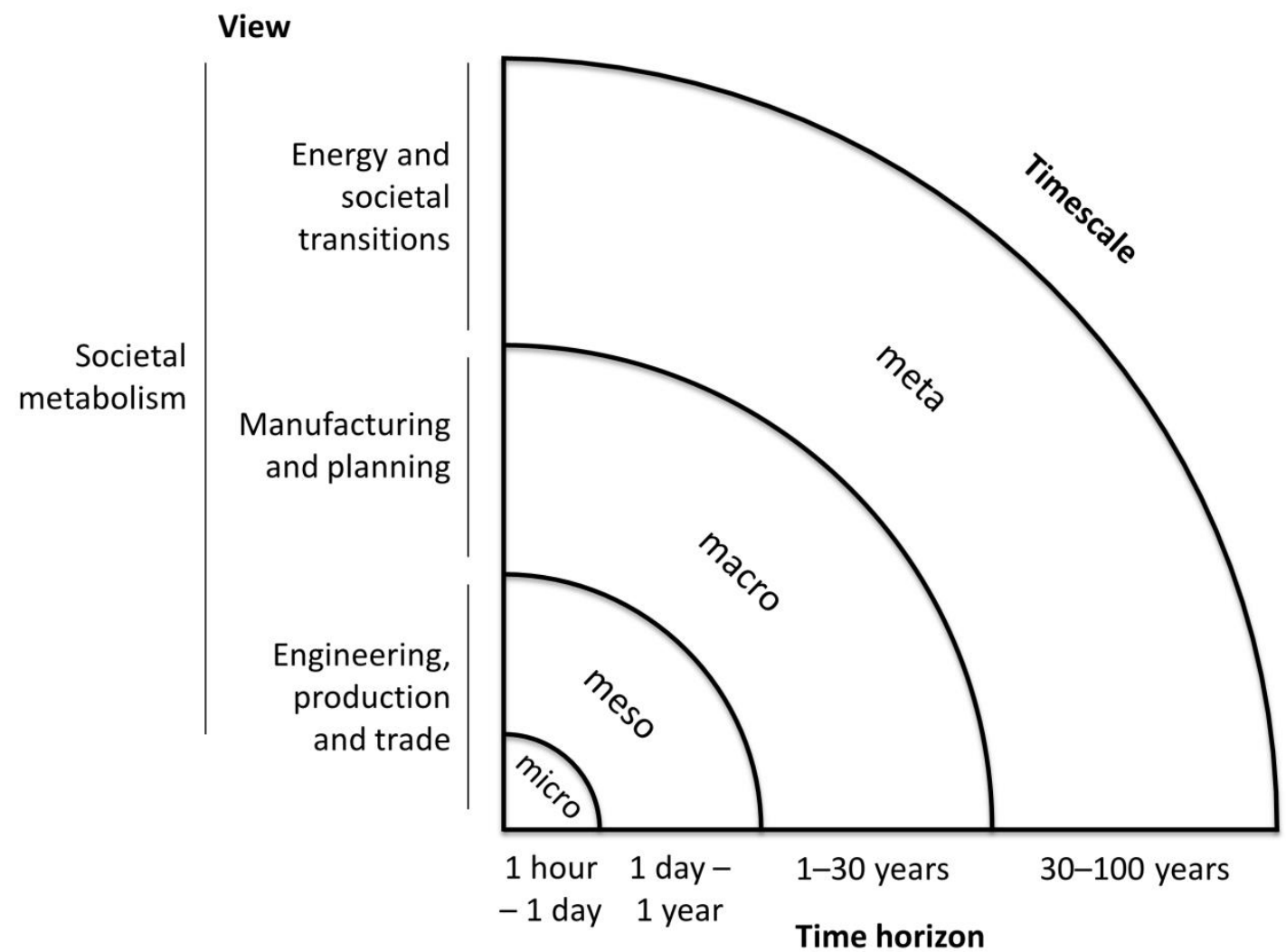

Fig. 1: The timescales of energy conversions in human societies and their associated views

The remainder of this section details the various timescales at which exosomatic energy conversions can be perceived.

2.1. Energy conversions perceived at the micro timescale (energy and power demand peaks) Energy conversions in societies can be perceived over a short timescale (e.g., one hour, one day). This micro temporal scale is useful to characterize changes on the patterns of production and consumption of ECs (energy carriers) happening at a smaller scale than the year, that is typically used in energy analysis. For instance, on the supply side, the generation of electricity using wind or solar energy can vary broadly during the day and over the season 
as it depends on the availability of the physical gradients, in that case wind speed and solar irradiation, creating peaks or shortages of production. On the energy demand side, the peak of consumption of electricity in households occurs at a given hour during the day and typically lasts less than one hour. Over the seasonal period, the peak of consumption by a group of households typically occurs in days of hottest or coolest temperatures depending on the season being summer or winter.

The existence of peaks of energy consumption implies the existence of peak of power demand making possible the energy conversions. For instance, in the agricultural sector, the peak in power demand happens during the season of harvesting which implies that either animal or mechanical power shall be available at that period (Giampietro el al. 2012). The existence of peaks of power demand implies in return another issue of 'stand-by power capacity' that is the amount of unused power capacity in other periods. In fact, whereas the generation energy flows can, in principle, match patterns of consumption, power capacity (converters) have to be produced-and in some cases maintained-even if they are unused over large periods of time. For this reason, the requirement and availability of power capacity is a crucial piece of information in sustainability assessment, although its formalization can require to be performed at a longer timescale in some cases. In fact, it should be noted that peaks of energy and power demand can have different durations depending on the types of end uses performed in the various societal compartments (households, services and government, agriculture and fisheries, building and manufacturing, energy and mining).

The micro timescale of energy conversions is therefore useful to account for the existence of (short) peaks and shortages in the production and consumption of ECs inside the different compartments of society. It is typically adopted by the engineering perspective inside the energy supply sector to meet the demand. Adopting such a short timescale makes it possible to also assess the performance of energy converters as regard their ability to meet the patterns of consumption of energy. However, this timescale is not sufficient for assessing the performance of energy supply systems from a societal metabolism perspective, something that requires longer timescales of analysis.

\subsection{Energy conversions perceived at the meso timescale (average supply and demand of energy flows)}

Second, energy conversions in societies can also be perceived over a longer timescale (e.g., one month, one year). The meso timescale of analysis allows assessing the average production and consumption of energy, typically over the duration of one year. This is the temporal scale typically adopted by energy analysts in the scientific community, statistical offices, international organizations and energy companies. It is useful to characterize the average annual consumption of ECs among the various metabolic compartments of society, 
as well as the annual requirements of primary energy by each energy supply systems on the supply side.

However, at this timescale it is necessary to consider the consumption of 'energy for energy', that is, the internal consumption of ECs by the energy supply sector for delivering the net surplus of ECs to the rest of society. In addition, given that the use of any energy form requires the use of an exosomatic energy converter adopting this timescale requires accounting for the amount of power capacity needed to perform societal functions using ECs.

At this timescale, energy converters energy and supply systems are considered as fund elements - their identity is assumed to remain unchanged during the timescale of analysiswhereas energy flows are considered as flow elements as they are metabolized by those converters - their identity is transformed (e.g., primary energy to energy carrier, energy carrier to end use). As energy converters and systems are fund elements, the analysis only considers their requirement and availability, disregarding their production and maintenance something which requires an even longer time horizon.

The meso timescale of energy conversions is typically adopted in energy planning, production and trade. Moreover, it is very useful to assess the performance of energy-supply systems, that is, their viability and desirability within the energy supply sector from a societal metabolism view (Diaz-Maurin and Giampietro 2013b, Diaz-Maurin 2013). In addition, it is also adopted by the end users having to anticipate longer peaks of energy and power demand, especially in productive sectors like in the agricultural sector. However it is not sufficient to fully characterize power capacity from a societal metabolism view.

\subsection{Energy conversions perceived at the macro timescale (life cycles of converters)}

Third, energy conversions can be perceived over a broader timescale that focuses on the production and maintenance of energy converters. The lifetime of converters dissipating energy carriers can vary broadly. For instance, an incandescent light bulb lasts about one year, a mobile phone about two years, a microwave about 5 years, a car about 10 years... It should be noted that in some cases the replacement cycle of goods-that include energy converters - can be driven by 'planned obsolescence' rather than by naturally-occurring obsolescence, which is not necessarily physical but can also be moral (London 1932).

The macro timescale can therefore span from one year to several decades depending on the purpose of the analysis. A typical scale of 10 years is considered as adequate to account for the production and maintenance of energy converters in an assessment. However, the choice of a fixed scale of analysis entails an ambiguity given that different converters have different lifetimes. This choice implies that converters shall be accounted several life cycles during the time horizon of analysis. 
At this timescale, energy converters dissipating energy carriers are considered as flow elements as their identity changes over the time horizon of analysis that is in the order of magnitude of their lifetime. That is, beyond-or within - this period the converter becomes obsolete and has to be replaced.

The extension of the time horizon of analysis requires considering another relevant flow of energy -in addition to the 'energy for energy' loop-corresponding to the energy required to make and maintain the power capacity required to convert an energy input into a flow of applied power. Thus, the analysis of the exosomatic flows at macro scale has to include the production and maintenance of power capacity required for energy conversion in addition to the generation of ECs.

This timescale is typically considered by the manufacturers in charge of producing the energy converters. In addition, it is particularly useful to assess the investment required to make and maintain the converters both in biophysical and economic terms in the societal metabolism view.

\subsection{Energy conversions perceived at the meta timescale (energy and societal transitions)} Last, when assessing the energetics of human societies in relation to energy and societal transitions one has to adopt a perception of energy conversions over an even larger timescale. Indeed, energy transitions refer to a large scale shift to a different mix of energy supply systems processing primary energy sources to generate energy carriers. Consequently, the meta timescale of analysis focuses on the energy supply systems generating ECs ('power capacity hypercyclic', see Section 3) that generally have longer lifetimes than the energy converters consuming ECs ('power capacity dissipative'). For instance, an offshore oil-drilling rig has a lifetime of about 20 years; a conventional thermal power plant a lifetime of about 30 years; whereas a nuclear power plant can operate up to 60 years.

Yet, the sole consideration of the lifetime of the plant generating an energy carrier is not sufficient to characterize an energy supply system as a whole. The complete representation of energy supply systems requires considering all the various unit operations required for the system to operate (Diaz-Maurin and Giampietro 2013b).

Moreover, considering the energy conversions involved in an energy transition implies considering the various energy supply systems making up the whole energy supply sector. In fact, the average time of an energy transition requires about a century (Smil 2010). For instance, in the case of nuclear energy systems, the transition of the overall nuclear-fuel cycle takes about 100 years (Kazimi et al. 2011) - disregarding the problem of handling radioactive waste over hundred thousands of years (Diaz-Maurin and Kovacic 2015)! - which sets the time horizon of analysis of the whole energy supply sector. 
The meta timescale can therefore span from several decades to one century corresponding to the period through which the energy supply sector or the whole society can be entirely transformed.

The meta timescale is useful to assess the investment required to make and maintain an energy supply system as a whole (e.g., the evaluation of the production factors required to reproduce the nuclear energy system or the fossil-fuel system used for generating electricity; e.g., see Diaz-Maurin and Giampietro 2013b), something very important for the discussion over the energy transition of human societies. Yet considering such a long timescale poses several epistemological problems in sustainability assessment.

First, at this timescale, the energy supply systems cannot be considered as fund elements anymore-that must remain unchanged over the time horizon of the analysis. Rather they have to be considered as flow elements as they are reproduced one or several times over the time horizon of the analysis. The absence of fund elements at this scale entails that there is no external referent to which flows can be compared (see Fig. 2c). In other words, energy systems - like human activity and land use - can still be considered as external referent, but their definition is affected by high levels of uncertainties which would affect the robustness of the analysis. In such a situation, one reaches the limits of performing quantitative analysis in sustainability assessment as shown below.

Second - an even deeper epistemological issue - the time horizon of a century exceeds, by far, the capability of human societies to organize themselves around such long time periods. This limitation is mainly due to the unavoidable expiration date of available information about the characteristics of local processes over a long period as well as the inescapable limit set by the life expectancy of human beings, letting alone the issue of fast-changing political goals at shorter time periods. As a matter of fact, at this scale, the identity of the societal compartments may change during the time period of analysis, entailing a fuzzy definition over their boundaries and size (see Fig. 2c). Consequently, although the societal functions may remain over this time period (human societies will still need food, water and energy coming from specialized compartments to operate in the next century), this shows the limits of performing quantitative sustainability assessment from a societal metabolism view over such a large time horizon given the changing identity of its internal structures. For this reason, this timescale is labeled as meta(physical) as it refers to something that 'exists' but that cannot be 'seen'. That is, the system can still be perceived in semantic terms (meaning) but cannot be formalized in quantitative terms (representation) anymore (for a recent discussion over the meaning and representation of systems, see Allen and Giampietro 2014). 


\section{Power capacity: concept, types and assessment methods}

\subsection{The concept of power capacity}

There exist various definitions and related units of measurement of power. For instance, power can come from machines, animals or humans, and can refer to various forms of energy as mechanical power or electrical power. The ambiguity about the definition and measurement of power refers back to the impossibility to give a substantive quantitative definition to energy (for a detailed discussion about this issue, see Diaz-Maurin and Giampietro 2013a) given that power corresponds to an amount of energy transformed per unit of time.

In this paper, the concept of power is considered in the view of societal metabolism (Giampietro and Mayumi 2000, Giampietro et al. 2009), specifically in its role in the energetic metabolism of human societies. In this context, the concept of power capacity refers to the installed technical capital able to convert a given quantity of exosomatic energy flow at a given timescale to provide useful functions ('end uses'). It is expressed in Watt or Watt-equivalent depending on the assessment method used (see Section 3.3). Power capacity is one of the production factors - along with energy flows, water flows, money flows, human time uses, land uses, etc. - required by the socio-economic process of human society to reproduce itself (Giampietro et al. 2011, Giampietro et al. 2014). The term power capacity started only recently to be considered in the field of multi-scale integrated assessment as a production factor for the study of the energetic metabolism of human societies (Giampietro et al. 2012). It then has been included as part of the general energy scheme proposed by Mayumi and Giampietro (2014) and has been commonly accounted for in most recent energetic studies (e.g., Giampietro and Diaz-Maurin 2014, Serrano-Tovar et al. 2014, Madrid-Lopez et al. 2014, Diaz-Maurin et al. 2014). Yet, power capacity certainly is one of the production factors of socio-economic systems which has been the least explored and understood so far. A first attempt to provide an explicit accounting method for power capacity was made by Diaz-Maurin (2013).

The following sections extend further the existing work made on power capacity by proposing (1) a clear definition over the different types of power capacity, and (2) an accounting scheme for the systemic formalization of power capacity in energetic analyses.

\subsection{The different types of power capacity}

Power capacity refers to the energy converters ('structures' in its literal sense) transforming energy flows to maintain societal functions. It is not to be confused with the concept of power level (or metabolic rate) which refers to an assessment of the pace of consumption of energy flows in relation to human time (see Section 2). That is, although their formalization refers to commensurable quantities (same dimension), power capacity (a fund element) and power level (a flow/fund ratio) are two non-equivalent quantitative information; the former being a production factor whereas the latter being an indicator in metabolic studies. 
Keeping this distinction in mind at all times, power capacity can refer to various types of exosomatic converters: (1) on the energy consumption side (e.g., cars, planes, cell phones, electric drills), energy converters that consume ECs to express specific functions ('end uses'; e.g., transporting, cooking, washing) on the various compartments of society; and (2) on the energy supply side (e.g., refineries, power plants), energy systems that convert primary energy sources into ECs (e.g., electricity, heat, fuels) to be delivered to the society by the energy supply sector. The power capacity used for energy consumption is labeled PCD (power capacity dissipative), whereas the power capacity required for energy supply is labeled PCH (power capacity hypercyclic).

It should be mentioned that given the supply of energy requires an internal consumption of ECs (the internal loop of 'energy for energy') the procedure also applies to the energy supply sector. Characterizing the EM (energy and mining) compartment-to which the energy supply sector belongs - therefore requires both an assessment of PCH used for energy generation and an assessment of PCD used for its internal energy consumption. The energy supply sector is at the crossroad of the distinction between these two types of power capacity.

Whereas PCD is required in all societal compartments for consuming ECs, $\mathrm{PCH}$ is required only in the EM compartment for generating ECs. However, all converters and systems associated with power capacity (e.g., appliances, machines, power plants) are manufactured inside one single BM (building and manufacturing) compartment.

The following figure shows the requirements of the two types of power capacity by the various compartments of society. To better understand the role of power capacity in the socio-economic process the figure uses the following three timescales of analysis presented in Section 2: (i) the meso timescale (time horizon, $\delta \mathrm{t}=1$ year), where the arrows represent ECs as flows generated by the EM compartment and fed to all compartments (fig. 2a); (ii) the macro timescale ( $\delta \mathrm{t} \approx 10$ years), where the arrows represent $\mathrm{PCD}$ as flows generated by the BM compartment and fed to all compartments (fig. $2 \mathrm{~b}$ ); and (iii) the meta timescale ( $\delta \mathrm{t} \approx 30$ 100 years), where the arrow represents $\mathrm{PCH}$ as flows generated by the BM compartment and fed only to the EM compartment (fig. 2c). In this figure, arrows represent only flows going to/from the compartment under focus ('interaction' in the energy systems language), hence disregarding interactions between compartments over other dimensions (e.g., water, food, human activity, economic activity, land use). Flows generated by the compartment under focus are delivered to the other societal compartments (identified as 'consumers' as regard those flows). Plain arrows represent flows that metabolize at the considered timescale whereas dashed arrows represent flows that metabolize at shorter timescales, hence flows that cannot properly be assessed. The dashed symbols used in Fig. $2 \mathrm{c}$ indicate the fuzzy boundaries (size) of the societal compartments at the meta timescale (see Section 2.4). 


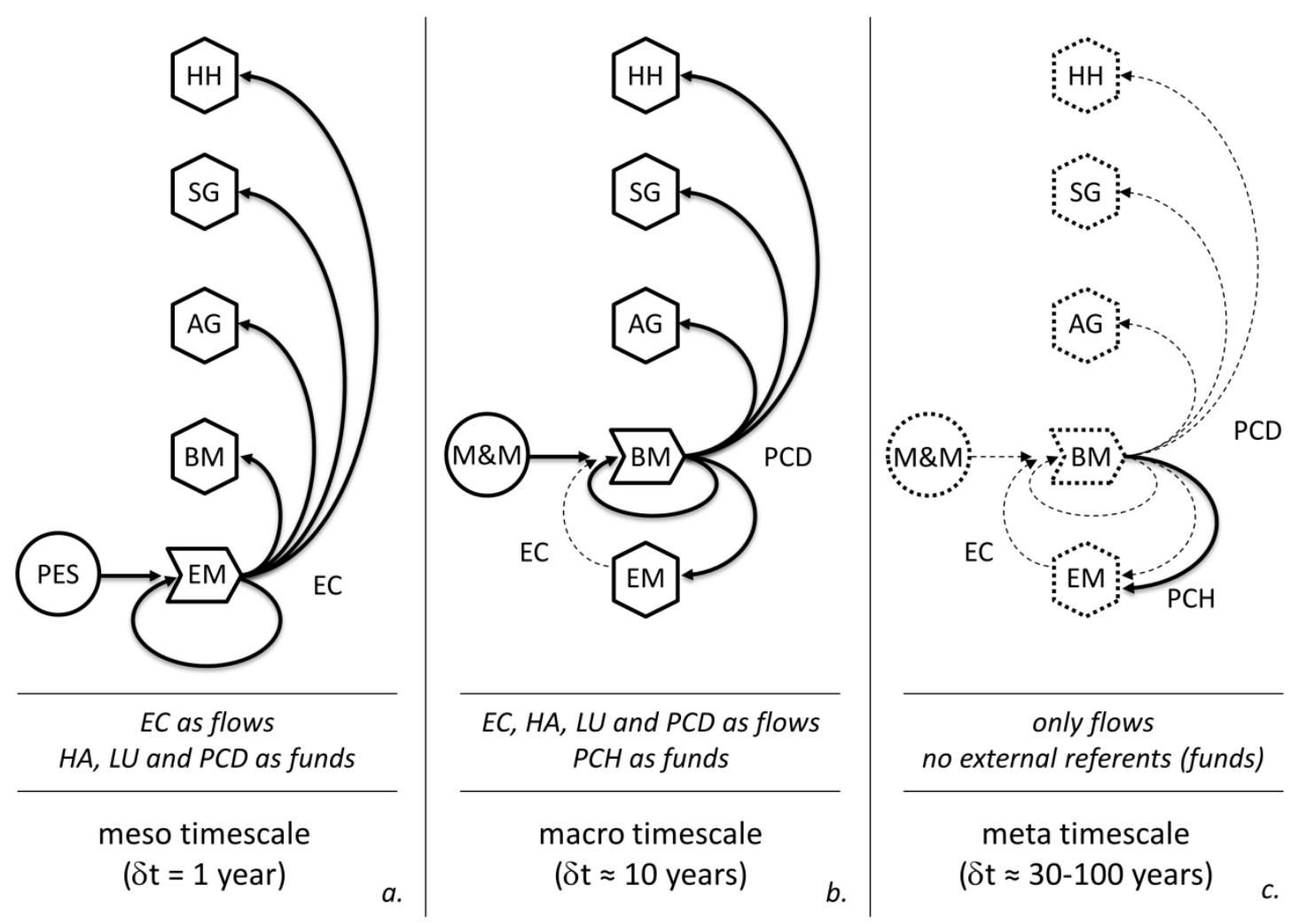

Fig. 2: Power capacity across societal compartments and timescales of analysis

Note: The figure uses the energy systems language proposed by H.T. Odum (1971) as a common denominator expressing all the flows and processes together in order to understand a whole system and the full interaction of its parts (Brown 2004).

Abbreviations used: AG, agriculture and fisheries; BM, building and manufacturing; EC, energy carriers; EM, energy and mining; $H A$, human activity; $H H$, households; $L U$, land use; $M \& M$, minerals and materials; $P C D$, power capacity dissipative; $P C H$, power capacity hypercyclic; PES, primary energy sources; SG, services and government.

Following the distinction between PCD and PCH made in Section 3.2, Figure 3 presents a taxonomy of the various types of power capacity from a societal metabolism view. 


\section{Power Capacity in Production (EM sector only)}

Energy supply systems* (e.g. a power plant, a refinery)

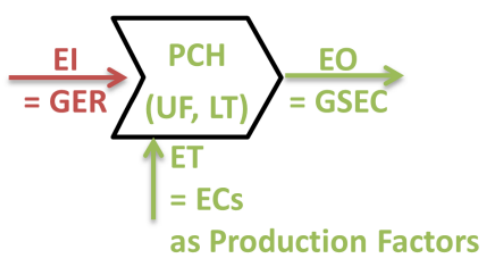

\begin{tabular}{c|c|c}
\hline IPCH & PCH & OPCH \\
\hline $\begin{array}{c}\text { "Virtual capacity } \\
\text { to dissipate } \\
\text { primary energy and } \\
\text { production factors" }\end{array}$ & $\begin{array}{c}\text { "Maximum capacity } \\
\text { to generate } \\
\text { energy carriers" }\end{array}$ & $\begin{array}{c}\text { "Actual capacity } \\
\text { to generate } \\
\text { energy carriers" }\end{array}$ \\
\hline $\begin{array}{c}\text { FLOW element } \\
\text { fharacterizing the } \\
\text { FUNCTION of the } \\
\text { energy system }\end{array}$ & $\begin{array}{c}\text { FUND element } \\
\text { characterizing the } \\
\text { STRUCTURE of the } \\
\text { energy system }\end{array}$ & $\begin{array}{c}\text { FLOW element } \\
\text { characterizing the } \\
\text { FUNCTION of the } \\
\text { energy system }\end{array}$ \\
\hline $\begin{array}{c}\text { Virtual } \\
\text { (indirectly measured } \\
\text { through El and ET) }\end{array}$ & $\begin{array}{c}\text { Installed } \\
\text { (known by design) }\end{array}$ & $\begin{array}{c}\text { Actual } \\
\text { (indirectly measured } \\
\text { through EO) }\end{array}$ \\
\hline
\end{tabular}

Power Capacity

in Consumption (all sectors)

Energy converters

(e.g. a cell phone, an electric drill, a car, a plane)

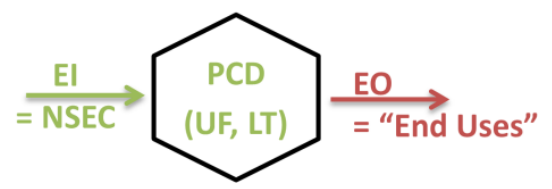

For each type of $E C=($ electricity, process heat, fuels)

\begin{tabular}{c|c}
\hline PCD & IPCD \\
\hline $\begin{array}{c}\text { "Maximum capacity } \\
\text { to dissipate } \\
\text { energy carriers" }\end{array}$ & $\begin{array}{c}\text { "Actual capacity } \\
\text { to dissipate } \\
\text { energy carriers" }\end{array}$ \\
\hline $\begin{array}{c}\text { FUND element } \\
\text { characterizing the } \\
\text { STRUCTURE of the } \\
\text { energy converter }\end{array}$ & $\begin{array}{c}\text { FLOW element } \\
\text { characterizing the } \\
\text { FUNCTION of the } \\
\text { energy converter }\end{array}$ \\
\hline $\begin{array}{c}\text { Installed } \\
\text { (known by design) }\end{array}$ & $\begin{array}{c}\text { Actual } \\
\text { (indirectly measured } \\
\text { through EI) }\end{array}$
\end{tabular}

Fig. 3: Taxonomy of power capacity for its use in sustainability assessment

Abbreviations used: EC, energy carriers; El, energy input; EM, energy and mining; EO, energy output; ET, energy throughput; EU, end uses; GER, gross energy requirement; GSEC, gross supply of energy carrier; IPCD, input of power capacity dissipative; IPCH, input of power capacity hypercyclic; LT, lifetime; NSEC, net supply of energy carrier; OPCH, output of power capacity hypercyclic; PCD, power capacity dissipative; PCH, power capacity hypercyclic; UF, utilization factor.

The taxonomy of power capacity presented in Fig. 3 makes it possible to describe the structure and functions of the energy supply systems used on the energy production side and of the energy converters used on the energy consumption side. Information about the structure related to power capacity is known by design (installed PCH and PCD). Information about the actual power capacity used to generate and dissipate energy carriers (OPCH and IPCD respectively) requires specific assessment procedures. Information about the virtual capacity used to dissipate primary energy and production factors (IPCH) requires in addition a convention about the evaluation of the energy input that is in the form of gross energy requirement (primary energy).

\subsection{Assessment methods of power capacity}

Some ambiguity arose in previous energetic studies considering power capacity as a production factor of the socio-economic process. For instance, Mayumi and Giampietro (2014: 63) noted that "in relation to Power Capacity it is important to be aware of the approximations implied by the assessment methods". Given this ambiguity, no power capacity dissipative at all was indicated by the authors for the EM compartment in their general energy accounting scheme. Even though those approximations were already 
acknowledged in the past (see Chapter 5 in Giampietro et al. 2012), they have not been further investigated to date. This section intends to address this issue by providing a systemic way to assess power capacity.

Two accounting methods for power capacity can be used whether the assessment is made from the bottom-up or from the top-down. The advantage of providing two distinct accounting methods is that the assessment of power capacity may be cross-checked, although only in the ideal situation where data is fully available and both methods can be used. When data is scarce (e.g., when no statistics are available at the aggregated level, or when there is no information about the converters used at the local level), power capacity may still be evaluated as a proxy considering either one or the other of the proposed accounting methods.

Adopting the taxonomy presented in Section 3.2, we present below the two accounting methods of power capacity whether the assessment refers to:

(1) the energy consumption side - PCD can be assessed using:

(i) a CBE (converter-based evaluation) method (bottom-up approach) based on the information gathered about the installed capacity of converters consuming electricity (e.g., dishwashers, air-conditioners, computers), fuels (e.g., planes, cars, trucks) or process heat (e.g., furnaces, heaters, ovens). ${ }^{1}$ This information is usually provided by the manufacturers on the technical specifications of the converters where the power capacity is expressed in Watts (W) or a unit of equivalence (e.g., horsepower). For instance, a Chevrolet Aveo 1.3 VCDi has a maximum power of 94 brake horsepower (bhp), which corresponds to $70 \mathrm{~kW}$ (Autocar.co.uk 2014).

The CBE method used for assessing the overall PCD in each societal compartment $i$ consuming a given EC $\mathrm{j}$ (electricity, heat or fuels) consists in the following steps:

* STEP \#1: Sum of the individual power capacities (in $\mathrm{W}^{2}$ ) of every converters of type $\mathrm{k}$ (e.g., cars, planes, computers, coffee machines, etc.) using a given EC $\mathrm{j}$ inside compartment $\mathrm{i}$ (bottom-up):

\footnotetext{
${ }^{1}$ There is a potential confusion regarding the meaning of heat in the assessment of PCD. In this assessment, heat refers to the energy carrier ('process heat', $\mathrm{ET}_{\mathrm{i}, \mathrm{h}}$ ) consumed by the converter under study and not to the end use (e.g., cooking, heating) delivered by this converter. Hence, the proposed accounting framework of PCD is defined by the type of EC it requires to operate (electricity, heat or fuels), not by the typologies of end uses (motion, lighting, heating, etc.) provided.

${ }^{2}$ Regarding the labels used to define power capacity, the International Bureau of Weights and Measures recommends that further information about a quantity should not be attached to the unit symbol (e.g., by using $\mathrm{kW}_{\mathrm{e}}$ ), but instead to the quantity symbol (i.e., $\mathrm{P}_{\text {thermal }}=270 \mathrm{~W}$ rather than $\mathrm{P}=270 \mathrm{~W}_{\mathrm{th}}$ ) and regards these symbols as incorrect (source: http://en.wikipedia.org/wiki/Watt\#Electrical_and thermal watts). We follow this recommendation-except for the units of energy forms due to the ambiguity of the concept of energy 


$$
P C_{i, j}=\sum_{k}\left[n_{i, j, k} \times P C_{i, j, k}\right]
$$

where $n_{i, j, k}$ corresponds to the number of converters of type $\mathrm{k}$ of individual capacity $P C_{i, j, k}$ (known by design).

* STEP \#2: The average annual energy input (EI) required by every converters of type $k$ is then obtained using the following relation:

$$
P C_{i, j, k}=\frac{E I_{i, j, k}}{3600 \times U F_{i, j, k} \times 8760}
$$

where:

$E I_{i, j, k}$ is expressed in J-EC/y (joules of energy carriers per year), and $U F_{i, j, k}$ (in \%) corresponds to the average annual utilization factor of converters of type $\mathrm{k}$ that is the product of two other factors:

$$
U F_{i, j, k}=O L_{i, j, k} \times C L_{i, j, k}
$$

where:

$O L_{i, j, k}$ (operating load, in \%) corresponds to the average number of hours of actual use of the converters of type $k$ in a year divided by 8760 hours per year, and $C L_{i, j, k}$ (capacity load, in \%) corresponds to the average fraction of the maximum power capacity of the converters of type $k$ used over the year.

This step requires information on consumption behavior (hours of use, $\mathrm{km}$ travelled, etc.).

* STEP \#3: The corresponding $E I_{i, j}$-evaluated from the bottom-up as $\sum_{k}\left[E I_{i, j, k}\right]$-is then checked against the known $E T_{i, j}$-total requirement of a given $\mathrm{EC}$ inside compartment $\mathrm{i}$, expressed in J-EC/Y-obtained at the aggregated level: fraction of $E T_{i, j}$ covered by $E I_{i, j}$. This step requires having performed the assessment of the energetic metabolism of the system from the top-down using the energy grammar accounting approach (Diaz-Maurin and Giampietro 2013b, Giampietro and Diaz-Maurin 2014).

* STEP \#4: Then, the maximum (or installed) power capacity (in W) of compartment i to dissipate a given EC $\mathrm{j}$ is obtained proportionally:

$$
P C D_{i, j}=\frac{E T_{i, j} \times P C_{i, j}}{E I_{i, j}}
$$

* STEP \#5: Similarly, the actual power capacity (in W) of compartment i dissipating a given EC $\mathrm{j}$ is obtained using one of the following relations:

$$
I P C D_{i, j}=\frac{E T_{i, j}}{3600 \times 8760}
$$




$$
I P C D_{i, j}=P C D_{i, j} \times U F_{i, j}
$$

where $U F_{i, j}$ corresponds to the average annual utilization factor of converters at the level of compartment $\mathrm{i}$ for the use of a given EC $\mathrm{j}$.

The CBE method is preferred for the assessment of PCD whenever information about the characteristics of the converters and about the energy consumption at aggregated level is available.

(ii) a FBA (flow-based approximation) method (top-down approach) by looking at the annual $E T_{i, j}$ (energy throughput), in J-EC/y, of a given EC $\mathrm{j}$ inside compartment $\mathrm{i}:^{3}$

$$
P C D_{i, j}=\frac{E T_{i, j}}{3600 \times U F_{i, j} \times 8760}
$$

Then, the actual power capacity $I P C D_{i, j}$ is evaluated using the same equations (5a) and (5b).

Whereas information on $E T_{i, j}$ usually is available at the aggregated level, in this top-down approach of assessment the average utilization factors $U F_{i, j}$ can only be evaluated by making assumptions about the average use of the converters. For this reason, it would be important to develop a bottom-up database of those factors in order to make more robust the assumption made using this FBA method. This further work on the calibration of the utilization factors is essential given their influence on the assessment of power capacities using this method.

The FBA method can be used as a first approximation of PCD in situations when the CBE method cannot be used in practice, that is, when information about converters is either not available or not considered. The FBA method provides a proxy of power capacity that can be expressed in Watts-equivalent (W-equ).

By using either one of the CBE and FBA methods, it then becomes possible to define the following vectors for every compartment $\mathrm{i}$ :

$$
\begin{aligned}
& P C D_{i}=\left[P C D_{i, \text { elec }} ; P C D_{i, \text { heat }} ; P C D_{i, f u e l s}\right] \\
& I P C D_{i}=\left[I P C D_{i, e l e c} ; I P C D_{i, \text { heat }} ; I P C D_{i, f u e l s}\right]
\end{aligned}
$$

\footnotetext{
${ }^{3}$ In this assessment, $E T_{i, j}$ corresponds to the direct consumption of ECs for the making and maintenance of the energy flows - the various processes required-hence disregards the indirect consumption of ECs for the making and maintenance of the funds - the various plants and facilities required-(see Diaz-Maurin and Giampietro 2013b). 
Given that the definition of power is affected by the same ambiguity as energy (see Section 2 ), it is recommended to keep separated at all times the assessment of the terms of $P C D_{i}$ and $I P C D_{i}$ referring to the converters using distinct ECs. This prevents the analyst from expressing the assessment using only one scalar which would imply falling into the problem of reductionism affecting conventional energy analysis (Mayumi and Giampietro 2014) and science more in general (Farrell et al. 2013). Any attempt to combine the assessments of power capacity across energy carriers should therefore be dealt with extreme care and, in all cases, keep information available about each term of the vectorial relations.

Finally, the total power capacity dissipative (TPCD) ${ }^{4}$ at the level of the whole society (WS) can be obtained by summing the power capacity of each individual compartment $\mathrm{i}$ :

$T P C D=\left[\sum_{i} P C D_{i, e l e c} ; \sum_{i} P C D_{i, h e a t} ; \sum_{i} P C D_{i, f u e l s}\right]$

(2) the energy supply side - PCH can be assessed using:

(i) a CBE method (bottom-up approach) based on the direct information gathered about the installed capacity of energy generation plants and equipment. Similarly to PCD, the CBE method for assessing $\mathrm{PCH}$ required in the energy supply sector to generate a given EC $\mathrm{i}$ (electricity, heat or fuels) consists in the following steps:

* STEP \#1: Sum of the individual power capacities (in W) of energy supply systems of type $\mathrm{j}$ (e.g., fossil fuels, biofuels, coal power, nuclear power, wind power) generating a given EC i inside the energy supply sector (bottom-up):

$P C_{i}=\sum_{j}\left[n_{i, j} \times P C_{i, j}\right]$

where $n_{i, j}$ corresponds to the number of energy supply systems of type $\mathrm{j}$ of individual capacity $P C_{i, j}$ (known by design).

It should be noted that the boundaries of an energy system, must be defined so that they include all relevant unit operations required to generate a given EC in a given context (country, type of design, etc.) as well as dealing with the waste and pollution generated in the process (e.g., 'mining/harvesting', 'refining/enriching', 'generating EC', 'handling waste/controlling pollution' - see Diaz-Maurin and Giampietro 2013b). For a detailed discussion over the definition of energy systems in the view of societal metabolism, see DiazMaurin and Giampietro 2013a.

${ }^{4}$ The total power capacity dissipative of the whole society can be labelled alternatively TPCD or PCD ${ }_{\text {ws. }}$ 
* STEP \#2: The average annual energy output (EO) generated by every energy supply systems of type $\mathrm{j}$ is then obtained using the following relation:

$$
P C_{i, j}=\frac{E O_{i, j}}{3600 \times U F_{i, j} \times 8760}
$$

where:

$E O_{i, j}$ is expressed in J-EC/y, and

$U F_{i, j}$ (in \%) corresponds to the average annual utilization factor of energy supply systems of type $\mathrm{j}$ that is the product of two other factors:

$$
U F_{i, j}=O L_{i, j} \times C L_{i, j}
$$

where:

$O L_{i, j}$ (operating load, in \%) corresponds to the average number of hours of actual generation by the energy supply systems of type $\mathrm{j}$ in a year divided by 8760 hours per year, and

$C L_{i, j}$ (capacity load, in \%) corresponds to the average fraction of the maximum power capacity of the energy supply systems of type j used over the year.

This step requires information on the performance of energy supply systems.

* STEP \#3: The corresponding $E O_{i}$-evaluated from the bottom-up as $\sum_{j}\left[E O_{i, j}\right]$-is then checked against the known $G S E C_{i}$ - gross supply of energy carrier $\mathrm{i}$, expressed in J-EC/yobtained at the aggregated level for every EC i generated: fraction of $G S E C_{i}$ covered by $E O_{i}$. This step requires having performed the assessment of the production of the various energy carriers by the energy supply sector as a whole using the energy grammar approach of accounting (Diaz-Maurin and Giampietro 2013b, Giampietro and Diaz-Maurin 2014).

* STEP \#4: Then, the maximum (or installed) power capacity to generate a given EC $\mathrm{i}$ is obtained proportionally:

$P C H_{i}=\frac{G S E C_{i} \times P C_{i}}{E O_{i}}$

* STEP \#5: Similarly, the actual power capacity (in W) of the energy supply sector generating a given $\mathrm{EC} \mathrm{i}$ is obtained using one of the following relations:

$$
\begin{aligned}
O P C H_{i} & =\frac{G S E C_{i}}{3600 \times 8760} \\
O P C H_{i} & =P C H_{i} \times U F_{i}
\end{aligned}
$$

where $U F_{i}$ corresponds to the average annual utilization factor of the energy systems generating a given $\mathrm{EC} i$. 
* STEP \#6: In addition, the virtual power capacity (in W) using primary energy sources (e.g., wind speed, potential energy from water, fossil fuels) and production factors (energy carriers of type $\mathrm{j}$ ) to generate a given $\mathrm{EC} i$ is obtained as:

$$
I P C H_{i}=\frac{E I_{i}+\sum_{j}\left[E T_{i, j} \times\left[\frac{G E R}{G E C}\right]_{j}\right]}{3600 \times 8760}
$$

where:

$E I_{i}$, (in J-GER/y) corresponds to the thermal equivalent of the average annual consumption of primary energy required to generate $G S E C_{i}$,

$E T_{i, j}$ (in J-EC/y) corresponds to the average annual consumption of each EC type $\mathrm{j}$ as production factors also required to generate $G S E C_{i}$,

$\left[\frac{G E R}{G E C}\right]_{j}$ corresponds to average conversion factor between gross energy requirement (GER, expressed in joules of thermal energy) and a given gross energy carrier (GEC, expressed in joules of EC) for every EC type $\mathrm{j}$ (e.g., electricity, heat, fuels). The evaluation of primary energy flows requires this convention given that they are 'virtual' quantities of energy not measurable as physical quantities in the external ('real') world (Giampietro and Diaz-Maurin 2014). This explains why IPCH is considered as a virtual power capacity characterizing the capacity of energy supply systems to dissipate primary energy and production factors per unit of time. As a first approximation, we can consider: $\left[\frac{G E R}{G E C}\right]_{\text {elec }}=2.61$, and $\left[\frac{G E R}{G E C}\right]_{\text {heat }}=$ $\left[\frac{G E R}{G E C}\right]_{\text {fuels }}=1.0$.

The CBE method is preferred for the assessment of $\mathrm{PCH}$ whenever information about the local energy supply systems and about the energy generation at aggregated level is available. It is typically used for evaluating the installed power capacity of power plants used for generating electricity. Indeed, the power capacity of a power plant refers to its ability to generate an EC at full capacity - which is generally labeled as such (e.g., a 1 GWe nuclear power plant) although it is not recommended to label the units (see note 2) - that is, information about the system is provided by the manufacturer. However, such information is not always expressed directly in Watt. In particular, the capacity of energy systems generating fuels and process heat typically is expressed in other units (e.g., barrels per day, horsepower, ${ }^{\circ} \mathrm{C}$ of exhaust heat) which required to be converted into Watts in the assessment of $\mathrm{PCH}$.

(ii) a FBA method by looking at the annual $G S E C_{i}$ generated by the energy supply sector, in $J-E C / y$ : 
$P C H_{i}=\frac{G S E C_{i}}{3600 \times U F_{i} \times 8760}$

Then, the actual power capacity $O P C H_{i}$ and virtual power capacity $I P C H_{i}$ are evaluated using the same equations (14a), (14b) and (15).

Similarly to the assessment of PCD, this top-down assessment of $\mathrm{PCH}$ requires making assumptions about the average utilization factors $U F_{i}$ of the energy supply systems generating EC types i. However in that case, this information typically is provided by statistics, at least for power generating plants. More in general, it would be important to develop a bottom-up database of the typical utilization factors of energy supply systems in order to make more robust the assumption made using this FBA method.

The FBA method can be used as a first approximation of $\mathrm{PCH}$ in situations where the $\mathrm{CBE}$ method cannot be used in practice, that is, when no actual energy systems are used to supply ECs (e.g., imports of ECs) or when information about the capacity of energy supply systems is not directly available (e.g., for the processes used in energy supply systems other than power plants, see Diaz-Maurin and Giampietro 2013b). In such situations, the FBA method provides a proxy of $\mathrm{PCH}$ which can be expressed in Watts-equivalent (W-equ).

By using either one of the CBE and FBA methods, it becomes possible to define the following vectors:

$$
\begin{aligned}
\text { TPCH } & =\left[\mathrm{PCH}_{\text {elec }} ; P C H_{\text {heat }} ; P C H_{\text {fuels }}\right] \\
\text { OPCH } & =\left[O P C H_{\text {elec }} ; O P C H_{\text {heat }} ; O P C H_{\text {fuels }}\right] \\
I P C H & =\left[I P C H_{\text {elec }} ; I P C H_{\text {heat }} ; I P C H_{\text {fuels }}\right]
\end{aligned}
$$

It should be noted that for the same reasons as for PCD, it is important to keep information available about each term of vectorial relations.

\subsection{Structure of a database on power capacity}

As shown in Section 3.3, in order to conduct a proper assessment of power capacity, it is necessary to gather various parameters related to the energy converters on the demand side and energy systems on the supply side. This information should be then organized in a coherent way so that parameters are correctly attributed to the corresponding structures

\footnotetext{
${ }^{5}$ The total power capacity hypercyclic of the energy supply sector can be labeled alternatively $\mathrm{TPCH}, \mathrm{PCH} \mathrm{EM}$ or $\mathrm{PCH}_{\text {Ws. }}$ 
and functions involved with the dissipation and generation of energy flows. Figure 4 summarizes the parameters required for each type of power capacity in a sustainability assessment.

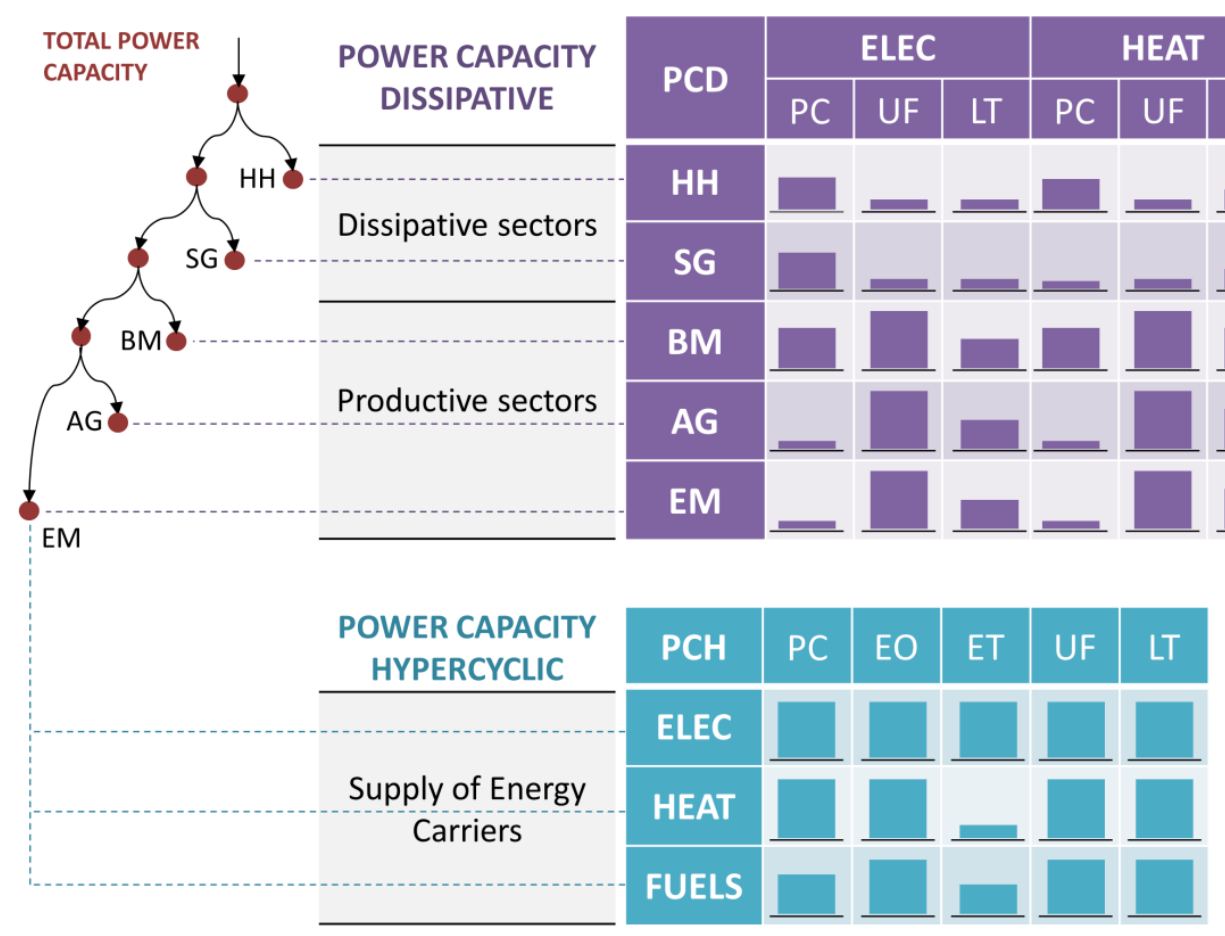

Fig. 4: Parameters required to conduct an assessment of power capacity

Abbreviations used: AG, agriculture and fisheries; BM, building and manufacturing; ELEC, electricity (energy carrier); EM, energy and mining; EO, energy output on the supply side (energy carrier); ET, energy throughput on the supply side (production factors in the form of energy carriers); FUELS, fuel products (energy carrier); HEAT, process heat (energy carrier); $\mathrm{HH}$, households; LT, average lifetime; PC, installed power capacity (dissipative or hypercyclic); SG, services and government; UF, average utilization factor.

The cells of Figure 4 indicate the typical intensity/value observed in modern societies of each one of the parameters relatively to the others. For instance, on the energy demand side, the dissipative compartments ( $\mathrm{HH}$ and SG) generally have higher installed power capacities per capita (PC) but lower utilization factors (UF) and lifetimes (LT) compared to the productive sectors (BM, AG and EM). On the energy supply side, the introduction of 'alternative' energy sources (e.g., renewables, biofuels, nuclear) generally having lower biophysical performance than conventional energy sources (fossil fuels) would have the general effects of increasing the average installed power capacities (PC) and production factors (here ET) required, whereas lowering the average utilization factors (UF) (e.g., intermittences of renewable energy systems) and lifetimes (LT) (e.g., smaller systems that need to be replaced more often). 


\section{Examples of power capacity assessments}

4.1. Assessment of the power capacity dissipative of an average household in the United States using a bottom-up approach

We provide below an example of the assessment of the power capacity of an average American household using the CBE method of assessment presented in Section 3.3.

In this exercise, we consider only the assessment of $P C D_{H H, \text { elec }}$ corresponding to the power capacity of the domestic appliances consuming electricity. This exercise does not consider the converters owned by the household and that consume heat and fuels (e.g., home heating systems, cooking stoves, cars, motorcycles).

Tab. 1 lists the electrical appliances and associated power capacity typically encountered in a household in the United States.

Tab. 1 Power capacity of electrical appliances of an average household in the United States

\begin{tabular}{|c|c|}
\hline Electric appliance & $\begin{array}{l}\text { Power capacity } \\
\text { (Watts) }\end{array}$ \\
\hline electric furnace & 17,221 \\
\hline central air conditioner & 5,000 \\
\hline clothes dryer & 3,400 \\
\hline oven & 2,300 \\
\hline dishwasher & 1,800 \\
\hline hair dryer & 1,538 \\
\hline coffee machine & 1,500 \\
\hline microwave & 1,500 \\
\hline space heater & 1,500 \\
\hline popcorn popper & 1,400 \\
\hline toaster oven & 1,200 \\
\hline iron & 1,100 \\
\hline toaster & 1,100 \\
\hline cooking range & 1,000 \\
\hline room air conditioner & 1,000 \\
\hline vacuum cleaner & 650 \\
\hline incandescent bulb (60-watt x 10 units) & 600 \\
\hline water heater & 479 \\
\hline clothes washer & 425 \\
\hline espresso machine & 360 \\
\hline dehumidifier & 350 \\
\hline plasma TV & 339 \\
\hline blender & 300 \\
\hline freezer & 273 \\
\hline LCD TV & 213 \\
\hline video game player & 195 \\
\hline refrigerator & 188 \\
\hline CFL bulb (60-watt equivalent x 10 units) & 180 \\
\hline monitor & 150 \\
\hline standard TV & 150 \\
\hline computer & 120 \\
\hline can opener & 100 \\
\hline electric blanket & 100 \\
\hline portable fan & 100 \\
\hline
\end{tabular}




\begin{tabular}{lr} 
stand mixer & 100 \\
curling iron & 90 \\
ceiling fan & 75 \\
humidifier & 75 \\
stereo & 60 \\
laptop & 50 \\
printer & 45 \\
DVR & 33 \\
aquarium & 30 \\
cable box & 20 \\
DVD player & 17 \\
satellite dish & 15 \\
VCR & 11 \\
clock radio & 10 \\
portable radio & 7 \\
wireless router & 7 \\
cell phone charger & 4 \\
cordless telephone & 3 \\
answering machine & 1 \\
\hline Total & $\mathbf{4 8 , 4 8 4}$ \\
\hline
\end{tabular}

Source: General Electric 2013.

Considering this simplified example of a household equipped with one unit of each type of appliances listed in Tab. 1 (except light bulbs for which we consider 10 units), we found that $P C D_{H, \text { elec }}$ is equal to $48.5 \mathrm{~kW}$ or $19.1 \mathrm{~kW}$ per capita, considering an average household size of 2.54 (US Census Bureau 2014).

Then, considering rough assumption over the average utilization factor of each types of electric appliances used in the household listed in Tab. 2, we perform a first approximation of the electricity consumed $\left(E I_{H H, e l e c}\right)$ and actual power capacity utilized $\left(I P C D_{H H, e l e c}\right)$.

Tab. 2 Approximation of the average utilization factor of electric appliances of an average household in the United States, and corresponding electricity consumption and actual power capacity

\begin{tabular}{lrlrrll}
\hline Electric appliance & $\begin{array}{l}\text { CL } \\
\text { (\%) }\end{array}$ & $\begin{array}{l}\text { Time } \\
\text { use } \\
\text { (hrs/y) }\end{array}$ & $\begin{array}{l}\text { OL } \\
\text { (\%) }\end{array}$ & $\begin{array}{l}\text { UF } \\
\text { (\%) }\end{array}$ & $\begin{array}{l}\text { EI } \\
\text { (MJ- } \\
\text { EC/y) }\end{array}$ & $\begin{array}{l}\text { IPCD } \\
\text { (W) }\end{array}$ \\
\hline electric furnace & $80 \%$ & 450 & $5 \%$ & $4 \%$ & 22,400 & 710 \\
central air conditioner & $80 \%$ & 600 & $7 \%$ & $5 \%$ & 8,700 & 276 \\
clothes dryer & $80 \%$ & 52 & $1 \%$ & $0.5 \%$ & 600 & 19 \\
oven & $80 \%$ & 208 & $2 \%$ & $2 \%$ & 1,400 & 44 \\
dishwasher & $100 \%$ & 183 & $2 \%$ & $2.1 \%$ & 1,200 & 38 \\
hair dryer & $80 \%$ & 8 & $0.1 \%$ & $0.1 \%$ & 40 & 1 \\
coffee machine & $80 \%$ & 15 & $0.2 \%$ & $0.1 \%$ & 70 & 2 \\
microwave & $80 \%$ & 183 & $2 \%$ & $1.7 \%$ & 800 & 25 \\
space heater & $80 \%$ & 1200 & $14 \%$ & $11 \%$ & 5,200 & 165 \\
popcorn popper & $80 \%$ & 52 & $0.6 \%$ & $0.5 \%$ & 300 & 10 \\
toaster oven & $80 \%$ & 8 & $0.1 \%$ & $0.1 \%$ & 30 & 1 \\
iron & $80 \%$ & 156 & $2 \%$ & $1.4 \%$ & 500 & 16 \\
toaster & $80 \%$ & 8 & $0.1 \%$ & $0.1 \%$ & 30 & 1 \\
\hline
\end{tabular}




\begin{tabular}{|c|c|c|c|c|c|c|}
\hline cooking range & $80 \%$ & 365 & $4 \%$ & $3.3 \%$ & 1,100 & 35 \\
\hline room air conditioner & $80 \%$ & 600 & $7 \%$ & $5.5 \%$ & 1,800 & 57 \\
\hline vacuum cleaner & $80 \%$ & 52 & $0.6 \%$ & $0.5 \%$ & 100 & 3 \\
\hline incandescent bulb (60-watt x 10 units) & $100 \%$ & 730 & $8 \%$ & $8.3 \%$ & 1,600 & 51 \\
\hline water heater & $80 \%$ & 15 & $0.2 \%$ & $0.1 \%$ & 30 & 1 \\
\hline clothes washer & $80 \%$ & 156 & $2 \%$ & $1.4 \%$ & 200 & 6 \\
\hline espresso machine & $80 \%$ & 15 & $0.2 \%$ & $0.1 \%$ & 20 & 1 \\
\hline dehumidifier & $80 \%$ & 900 & $10 \%$ & $8.2 \%$ & 1,000 & 32 \\
\hline plasma TV & $80 \%$ & 548 & $6 \%$ & $5.0 \%$ & 600 & 19 \\
\hline blender & $80 \%$ & 8 & $0.1 \%$ & $0.1 \%$ & negl. & negl. \\
\hline freezer & $80 \%$ & 8760 & $100 \%$ & $80 \%$ & 6,900 & 219 \\
\hline LCD TV & $80 \%$ & 548 & $6 \%$ & $5.0 \%$ & 400 & 13 \\
\hline video game player & $80 \%$ & 260 & $3 \%$ & $2.4 \%$ & 200 & 6 \\
\hline refrigerator & $80 \%$ & 8760 & $100 \%$ & $80 \%$ & 4,800 & 152 \\
\hline CFL bulb (60-watt equivalent $\times 10$ units) & $100 \%$ & 730 & $8 \%$ & $8.3 \%$ & 500 & 16 \\
\hline monitor & $80 \%$ & 520 & $6 \%$ & $4.7 \%$ & 300 & 10 \\
\hline standard TV & $80 \%$ & 548 & $6 \%$ & $5.0 \%$ & 300 & 10 \\
\hline computer & $80 \%$ & 520 & $6 \%$ & $4.7 \%$ & 200 & 6 \\
\hline can opener & $80 \%$ & 8 & $0.1 \%$ & $0.1 \%$ & negl. & negl. \\
\hline electric blanket & $80 \%$ & 46 & $0.5 \%$ & $0.4 \%$ & 20 & 1 \\
\hline portable fan & $80 \%$ & 200 & $2 \%$ & $1.8 \%$ & 60 & 2 \\
\hline stand mixer & $80 \%$ & 8 & $0.1 \%$ & $0.1 \%$ & negl. & negl. \\
\hline curling iron & $80 \%$ & 8 & $0.1 \%$ & $0.1 \%$ & negl. & negl. \\
\hline ceiling fan & $80 \%$ & 1800 & $21 \%$ & $16 \%$ & 400 & 13 \\
\hline humidifier & $80 \%$ & 900 & $10 \%$ & $8.2 \%$ & 200 & 6 \\
\hline stereo & $80 \%$ & 260 & $3 \%$ & $2.4 \%$ & 50 & 2 \\
\hline laptop & $80 \%$ & 1560 & $18 \%$ & $14 \%$ & 300 & 10 \\
\hline printer & $80 \%$ & 52 & $0.6 \%$ & $0.5 \%$ & negl. & negl. \\
\hline DVR & $80 \%$ & 110 & $1 \%$ & $1.0 \%$ & 20 & 1 \\
\hline aquarium & $80 \%$ & 8760 & $100 \%$ & $80 \%$ & 800 & 25 \\
\hline cable box & $80 \%$ & 548 & $6 \%$ & $5.0 \%$ & 40 & 1 \\
\hline DVD player & $80 \%$ & 110 & $1 \%$ & $1.0 \%$ & negl. & negl. \\
\hline satellite dish & $80 \%$ & 548 & $6 \%$ & $5.0 \%$ & 30 & 1 \\
\hline VCR & $80 \%$ & 110 & $1 \%$ & $1.0 \%$ & negl. & negl. \\
\hline clock radio & $80 \%$ & 8760 & $100 \%$ & $80 \%$ & 300 & 10 \\
\hline portable radio & $80 \%$ & 52 & $0.6 \%$ & $0.5 \%$ & negl. & negl. \\
\hline wireless router & $80 \%$ & 8760 & $100 \%$ & $80 \%$ & 200 & 6 \\
\hline cell phone charger & $80 \%$ & 520 & $6 \%$ & $4.7 \%$ & negl. & negl. \\
\hline cordless telephone & $80 \%$ & 260 & $3 \%$ & $2.4 \%$ & negl. & negl. \\
\hline answering machine & $80 \%$ & 5 & $0.1 \%$ & $0.0 \%$ & negl. & negl. \\
\hline Total/Average & $n / a$ & n/a & $n / a$ & $4.2 \%$ & 63,740 & 2,021 \\
\hline
\end{tabular}

Source: Own elaboration.

We now can compare the average electricity consumption El obtained from our bottom-up assessment with the average electricity consumption of households known from top-down national statistics. We found that our assessment $\left(\mathrm{EI}_{\mathrm{HH}, \mathrm{elec}, \mathrm{BU}}=25 \mathrm{GJ}\right.$-EC p.c.) overestimates the actual consumption of electricity in households $\left(\mathrm{EI}_{\mathrm{HH}, \mathrm{elec}, \mathrm{TD}}=16 \mathrm{GJ}\right.$-EC p.c., after US EIA 2009). This means that the average utilization factor of electric appliances in households is lower than the $4 \%$ obtained from our first approximation. In addition, the average American household may not be equipped with the same list of electric appliances. This has two 
implications for the assessment of power capacity. First, a sound power capacity assessment should build upon a bottom-up database looking at the actual utilization factors per types of energy converters in the country under study and which should be calibrated against topdown assessment of energy consumption. Second, the notion of average household is not enough and a robust metabolic study requires considering typologies of households (e.g., urban rich, urban poor, rural in subsistence) representative of actual end users.

\subsection{Assessment of the power capacity dissipative in Spain using a top-down approach}

We now provide an example of assessment of the power capacity dissipative in Spain for the year 2004 using the FBA method presented in Section 3.3.

Tab. 3 lists the energy carriers consumed (NSEC) in each one of the societal compartments and presents the corresponding assessment of actual power capacity dissipative (IPCD) for all compartments of Spain in the year 2004.

Tab. 3 NSEC and IPCD across societal compartments - Spain, Year 2004.

\begin{tabular}{|c|c|c|c|c|c|c|}
\hline & \multicolumn{3}{|c|}{$\begin{array}{l}\text { NSEC } \\
\text { (GJ-EC p.c./y) }\end{array}$} & \multicolumn{3}{|c|}{$\begin{array}{l}\text { IPCD } \\
\text { (kW-equ p.c.) }\end{array}$} \\
\hline & ELEC & HEAT & FUELS & ELEC & HEAT & FUELS \\
\hline Whole society & 23 & 30 & 50 & 0.73 & 0.95 & 1.59 \\
\hline Household sector & 5 & 10 & 13 & 0.16 & 0.32 & 0.41 \\
\hline Service \& government & 6 & 0 & 27 & 0.19 & 0 & 0.86 \\
\hline $\begin{array}{l}\text { Building and } \\
\text { manufacturing }\end{array}$ & 9 & 19 & 0 & 0.29 & 0.60 & 0 \\
\hline Agriculture & 0.5 & 1 & 2 & 0.02 & 0.03 & 0.06 \\
\hline Energy \& mining & 2 & 0 & 7 & 0.06 & 0 & 0.22 \\
\hline
\end{tabular}

Source: Giampietro and Diaz-Maurin 2014 (for NSEC); Own elaboration (for IPCD).

Note: In this simplified example, the consumption of fuels for transportation is accounted for in the SG (services and government) compartment (except for private transportation accounted for in the $\mathrm{HH}$ compartment). For this reason, fuel consumption in the building and manufacturing (BM) compartment $N S E C_{B M}$, fuels is considered as negligible, so does the corresponding power capacity.

Abbreviations used: ELEC, electricity (energy carrier); FUELS, fuel products (energy carrier); HEAT, process heat (energy carrier); IPCD, input of power capacity dissipative; NSEC, net supply of energy carriers.

For instance, the vector of actual power capacity IPCD in the household compartment $(\mathrm{HH})$ is equal to:

$I P C D_{H H}=\left[I P C D_{H H, \text { elec }} ; I P C D_{H H, \text { heat }} ; I P C D_{H H, f u e l s}\right]=[0.16 ; 0.32 ; 0.41] \mathrm{kW}$-equ p.c. 
Each term $I P C D_{H H, j}$ is evaluated using eq. (5a) where consumption of ECs $E T_{H H, j}$ is equal to (from Giampietro and Diaz-Maurin 2014):

$E T_{H H}=\left[E T_{H H, \text { elec }} ; E T_{H H, \text { heat }} ; E T_{H H, \text { fuels }}\right]=[5 ; 10 ; 13] \mathrm{GJ}-\mathrm{EC}$ p.c./y

Then the vector of maximum (installed) power capacity PCD in the same HH compartment is equal to:

$P C D_{H H}=\left[P C D_{H H, e l e c} ; P C D_{H H, \text { heat }} ; P C D_{H H, f u e l s}\right]=[6.3 ; 4.0 ; 26] \mathrm{kW}$ p.c.

Each term $P C D_{H H, j}$ is evaluated using eq. (6) where the following assumptions are made about the average utilization factors $U F_{H H, j}$ (from Giampietro and Diaz-Maurin 2014):

$U F_{H H}=\left[U F_{H H, \text { elec }} ; U F_{H H, \text { heat }} ; U F_{H H, f u e l s}\right]=[3 \% ; 8 \% ; 2 \%]$

As noted in Section 3.3, the average utilization factors $U F_{i, j}$ require assumptions which should be taken with care. Ideally, they should derive from a bottom-up database.

Tab. 4 lists the assumptions made as regard the average utilization factors (UF) and presents the corresponding assessment of maximum (installed) power capacity dissipative (PCD) for all compartments of Spain in the year 2004.

Tab. 4 UF and PCD across societal compartments - Spain, Year 2004.

\begin{tabular}{|c|c|c|c|c|c|c|c|c|c|c|c|c|}
\hline & \multicolumn{3}{|c|}{ ELEC } & \multicolumn{3}{|c|}{ HEAT } & \multicolumn{3}{|c|}{ FUELS } & \multicolumn{3}{|c|}{$\begin{array}{l}\text { PCD } \\
\text { (kW-equ p.c.) }\end{array}$} \\
\hline & $\begin{array}{l}\mathrm{OL} \\
(\%)\end{array}$ & $\begin{array}{l}\mathrm{CL} \\
(\%)\end{array}$ & $\begin{array}{l}\text { UF } \\
(\%)\end{array}$ & $\begin{array}{l}\text { OL } \\
(\%)\end{array}$ & $\begin{array}{l}\mathrm{CL} \\
(\%)\end{array}$ & $\begin{array}{l}\text { UF } \\
(\%)\end{array}$ & $\begin{array}{l}\text { OL } \\
(\%)\end{array}$ & $\begin{array}{l}\mathrm{CL} \\
(\%)\end{array}$ & $\begin{array}{l}\text { UF } \\
(\%)\end{array}$ & ELEC & HEAT & FUELS \\
\hline Whole society & - & - & - & - & - & - & - & - & - & 7.9 & 5.1 & 42 \\
\hline $\begin{array}{l}\text { Household } \\
\text { sector }\end{array}$ & 5 & 50 & 3 & 10 & 80 & 8 & 8 & 20 & 2 & 6.3 & 4.0 & 26 \\
\hline $\begin{array}{l}\text { Service \& } \\
\text { government }\end{array}$ & 40 & 50 & 20 & 20 & 80 & 16 & 20 & 30 & 6 & 0.95 & 0 & 14 \\
\hline $\begin{array}{l}\text { Building and } \\
\text { manufacturing }\end{array}$ & 75 & 80 & 60 & 75 & 80 & 60 & - & - & - & 0.48 & 1.0 & - \\
\hline Agriculture & 40 & 80 & 32 & 40 & 80 & 32 & 20 & 40 & 8 & 0.05 & 0.1 & 0.79 \\
\hline $\begin{array}{l}\text { Energy \& } \\
\text { mining }\end{array}$ & 75 & 80 & 60 & 75 & 80 & 60 & 50 & 40 & 20 & 0.11 & 0 & 1.1 \\
\hline
\end{tabular}

Source: Giampietro and Diaz-Maurin 2014 (for UF); Own elaboration (for PCD).

Abbreviations used: CL, capacity load; ELEC, electricity (energy carrier); FUELS, fuel products (energy carrier); HEAT, process heat (energy carrier); OL, operating load; PCD, power capacity dissipative; UF, utilization factor. 
4.3. Assessment of the power capacity hypercyclic of a nuclear power system using a bottomup approach

Last, we provide an example of assessment of the power capacity hypercyclic of a nuclear power system using the CBE method presented in Section 3.3.

Considering the case of a light-water reactor (LWR) power plant design, including nuclearfuel cycle without reprocessing, the plant has the following parameters:

Tab. 5 Parameters of a LWR power plant, including nuclear-fuel cycle without reprocessing.

\begin{tabular}{lrl}
\hline Parameter & Value & Unit \\
& & \\
\hline Direct fuel consumption (ET fuels & 250 & $\mathrm{GJ}-\mathrm{EC} / \mathrm{GWh}$ \\
Utilization factor (UF) & $79 \%$ & - \\
Plant capacity (PCH) & 1300 & $\mathrm{MW}$ \\
Electricity generated (GSEC) & 9000 & $\mathrm{GWh} / \mathrm{y}$ \\
\hline
\end{tabular}

Source: Diaz-Maurin and Giampietro 2013.

Abbreviations used: $\mathrm{ET}_{\text {fuels, }}$ energy throughput in the form of fuels; GSEC, gross supply of energy carrier; $\mathrm{PCH}$, power capacity hypercyclic; UF, utilization factor.

Considering these parameters, we can assess the power capacity hypercyclic of a nuclear power system.

First, the maximum (installed) power capacity $\mathrm{PCH}$ is given by the manufacturer as 1300 MW.

Then, using eq. (14a), the actual power capacity $\mathrm{OPCH}$ is evaluated as $1027 \mathrm{MW}$.

Last, using eq. (15), the virtual capacity IPCH is evaluated as $2854 \mathrm{MW}$, considering:

$E T_{\text {fuels }}=250 \mathrm{GJ}-\mathrm{EC} / \mathrm{GWh}$, and

$E I=3600 \times E O \times\left[\frac{G E R}{G E C}\right]_{\text {elec }}$

where:

$E O=G S E C=9000 \mathrm{GWh} / \mathrm{y}$, and

$\left[\frac{G E R}{G E C}\right]_{\text {elec }}=2.61$.

\subsection{Comparing the assessments}

The three assessments provided above serve the purpose of illustrating the accounting methods presented in Section 3.3. The comparison of these assessments allows identifying three important characteristics related to power capacity:

(1) Dissipative compartments use much more power capacity than productive sectors 
From Section 4.2, it is clear that the Households compartment uses much more power capacity per capita than any other societal compartment.

Second, when combining all dissipative compartments together (Households + Service and government), they represent about $90 \%$ of the total installed PCD:

$P C D_{H H+S G}=[7.3 ; 4.0 ; 40] \mathrm{kW}$ p.c. vs. $P C D_{B M+A G+E M}=[0.63 ; 1.1 ; 2.0] \mathrm{kW}$ p.c.

(2) The rate of use of power capacity is much higher in the dissipative compartments than in productive sectors

As observed in the previous point, the $\mathrm{HH}$ compartment requires much more $\mathrm{PCD}$ than the EM compartment.

$P C D_{H H}=[6.3 ; 4.0 ; 26] \mathrm{kW}$ p.c. vs. $P C D_{E M}=[0.11 ;$ negl. ; 1.1$] \mathrm{kW}$ p.c.

However, this picture changes to the opposite when looking at the requirement of power capacity per unit of human time of these two compartments. Indeed, considering the examples provided above, we find the following metabolic rates $M R_{i, j}$ of installed power capacity of type $i$ in compartment $j$ per unit of human time:

$M R_{P C D, H H}=P C D_{H H} / H A_{H H}=[0.81 ; 0.51 ; 3.3] \mathrm{W}$-equ $/ \mathrm{hr}$

vs.

$M R_{P C D, E M}=P C D_{E M} / H A_{E M}=[13 ;-; 139] \mathrm{W}$-equ $/ \mathrm{hr}$,

where human activity (HA) in those compartments is equal to (Giampietro and Diaz-Maurin 2014):

$H A_{H H}=7825 \mathrm{hrsp}$ p.c./y, and

$H A_{E M}=8 \mathrm{hrs} \mathrm{p.c./y.}$

The use of MRs to characterize the performance of compartments acting as organs of human society considered as a living system has been already investigated in the field of multi-scale integrated assessment (Giampietro et al. 2011, 2012, 2014). Available research in particular provides benchmark values for some flow/fund ratios (e.g., energy consumed per unit of human time, food produced per unit of land use). Yet, few empirical studies have been performed regarding fund/fund ratios that compare fund elements to each other (land, human time and power capacity). The example provided above of metabolic rates of power capacity requirement corresponds to a fund/fund ratio, that is, the amount of power capacity used per unit of human time.

The fact that the use of power capacity is much more intensive in the productive sectors (higher MRs) illustrates the existence of large amounts of stand-by power capacities in the dissipative compartments. The stand-by power capacity can be directly evaluated by looking 
at the low actual power capacity used (IPCD) in relation to the installed power capacity (PCD).

\section{(3) There exist large disparities over power capacity among countries}

Following the assessment of power capacity in an average household in the United States presented in Section 4.1, we find an installed power capacity using electricity $P C D_{H H \text {,elec }}$, after performing a top-down/bottom-up calibration on the average electricity consumption per capita, of $12 \mathrm{~kW}$ p.c.

This assessment indicates that power capacity using electricity in households in the United States is twice as much as the power capacity of the same compartment in Spain $\left(P C D_{H H, e l e c}=6.3 \mathrm{~kW}\right.$ p.c.). This means that an average household in the United States is equipped with about twice as much electric appliances than an average household in Spain that is another OECD country! This disparity, even among developed countries, illustrates how power capacity can be a key element in the sustainability assessment of modern societies.

\section{Conclusion}

One of the main lessons from Georgescu-Roegen's (1971) fund-flow scheme is that the economic process is not about producing goods and services but about producing the funds required by society to consume goods and services for its own reproduction. The reproduction of power capacity-being one of the key fund elements of human societiestherefore is an essential attribute to the study of the economic process and more broadly for the sustainability assessment of human societies.

As shown in this paper, power capacity can be a meaningful indicator of the level of development that should systemically be included as one of the key production factors in the sustainability assessment of socio-economic systems. The inclusion of power capacity in sustainability assessment would be very beneficial to the discussion over the energy and societal transitions as it makes it possible to consider the long-term effects of external constraints over the metabolism of human societies.

In the view of societal metabolism, studying the phenomenon of progressive depletion of fossil energy resources (also called 'peak oil') by focusing on the declining quality and quantities of energy flows alone does not seem to be sufficient to grasp the deeper consequences of this external constraint for the sustainability of human societies. A more systemic view requires extending the time horizon of analysis so as to consider the effects of peak oil on power capacity, which consists in embracing a demand-side view in addition to the supply-side view typically adopted when dealing with energy issues. 
Yet, the study of power capacity will need further empirical efforts before it can be systemically included in sustainability assessment. In particular, the framework proposed in this paper requires a calibration of the accounting methods bridging the top-down and bottom-up approaches of assessment across the various societal compartments and across different countries. The calibration can consist in comparing the energy input of the converters covered when assessing power capacity from the bottom-up with the total energy throughput of the studied compartment obtained by performing the energy grammar at the aggregated level (Diaz-Maurin and Giampietro 2013, Giampietro and DiazMaurin 2014). It requires in return building a database of power capacity and associated parameters both on the demand and supply sides. Although availability of data is key for this purpose, the general trend towards 'open data' and 'big data' could prove to be very handy toward that direction. The systemic calibration of the two proposed methods of assessment is essential for the establishment of a robust study of power capacity in the sustainability assessment of human societies.

Empirical efforts of collecting and calibrating data over power capacity should be considered as a priority in the field of energetics as it would have deep implications for our understanding of the evolution of human societies now and for in the future. By using information related to the level of power capacity used by socio-economic systems it would be possible to reconstruct their biophysical 'patterns of recorded information'. Human societies, like all living systems, use in fact such patterns to guide their process of selforganization (Diaz-Maurin and Giampietro 2013). Patterns of recorded information act as the memory of the energetics of living systems making possible for them to deal with different energy forms in the same way that, at the nano space-scale, neural circuits regulate the activity of biological neural networks. Reconstructing patterns of use of power capacity across societal scales would be very beneficial for the study of the role this factor played in the development of human societies and for facing the external constraints ahead.

\section{Acknowledgments}

I wish to thank Mario Giampietro and Alevgül H. Sorman for their previous work which paved the way toward the integration of power capacity in sustainability assessment. I also thank them for their comments on the earlier version of this manuscript. Shortcomings and misconceptions remain my own responsibility.

\section{Funding}

This research received no specific grant from any funding agency in the public, commercial, or not-for-profit sectors. 


\section{References}

Allen, T. F. H., \& Giampietro, M. (2014). Holons, creaons, genons, environs, in hierarchy theory: Where we have gone. Ecological Modelling 293(C), 31-41. doi:

10.1016/j.ecolmodel.2014.06.017.

Autocar.co.uk (2014) Chevrolet Aveo performance. http://www.autocar.co.uk/carreview/chevrolet/aveo/performance (accessed 05.03.15).

Brown, M.T. (2004). A picture is worth a thousand words: energy systems language and simulation. Ecological Modelling 178, 83-100. doi: 10.1016/j.ecolmodel.2003.12.008.

Diaz-Maurin, F. (2013, October). The Viability and Desirability of Alternative Energy Sources: Exploring the Controversy over Nuclear Power. (Ph.D. dissertation) Universitat Autònoma de Barcelona, Spain. http://www.educacion.es/teseo/mostrarRef.do?ref=1052415 (accessed 05.03.15).

Diaz-Maurin, F., \& Giampietro, M. (2013a). Complex Systems and Energy. In: Reference Module in Earth Systems and Environmental Sciences. Elsevier. doi: 10.1016/B978-0-12409548-9.01549-9.

Diaz-Maurin, F., \& Giampietro, M. (2013b). A “Grammar" for assessing the performance of power-supply systems: Comparing nuclear energy to fossil energy. Energy 49, 162-177. doi:10.1016/j.energy.2012.11.014.

Diaz-Maurin F., J. Cadillo Benalcazar, Z. Kovacic, C. Madrid, T. Serrano-Tovar, M. Giampietro, R.J. Aspinall, \& J. Ramos-Martin (2014). Chapter 14. The Republic of South Africa. In: Giampietro, M., Aspinall, R.J., Ramos-Martín, J., \& Bukkens, S.G.F. (Eds.). Resource Accounting for Sustainability: The Nexus between Energy, Food, Water and Land Use. London: Routledge, 250 pp.

Farrell, K., Luzzati, T., \& van den Hove, S. (Eds.). (2013). Beyond reductionism: a passion for interdisciplinarity. London; New York: Routledge.

General Electric (2013). http://visualization.geblogs.com/visualization/appliances/ (accessed 05.03.15).

Georgescu-Roegen, N. (1971). The entropy law and the economic process. Cambridge, MA: Harvard University Press.

Giampietro, M., Bukkens, S. G., \& Pimentel, D. (1993). Labor productivity: a biophysical definition and assessment. Human Ecology, 21(3), 229-260.

Giampietro M., \& Diaz-Maurin, F. (2014). Chapter 8. The Energy Grammar. In: Giampietro, M., Aspinall, R.J., Ramos-Martín, J., \& Bukkens, S.G.F. (Eds.). Resource Accounting for Sustainability: The Nexus between Energy, Food, Water and Land Use. London: Routledge, $250 \mathrm{pp}$.

Giampietro, M., \& Mayumi, K. (2000). Multiple-scale integrated assessment of societal metabolism: introducing the approach. Population and Environment, 22(2), 109-153. 
Giampietro, M., Mayumi, K., \& Ramos-Martin, J. (2009). Multi-scale integrated analysis of societal and ecosystem metabolism (MUSIASEM): Theoretical concepts and basic rationale. Energy 34(3), 313-322. doi:10.1016/j.energy.2008.07.020.

Giampietro, M., Mayumi, K., \& Sorman, A. H. (2011). The Metabolic Pattern of Societies: Where Economists Fall Short. London: Roultedge, 408 pp.

Giampietro, M., Mayumi, K., \& Sorman, A. H. (2012). Energy Analysis for a Sustainable Future: Multi-Scale Integrated Analysis of Societal and Ecosystem Metabolism. London: Routledge, $360 \mathrm{pp}$.

Giampietro, M., Aspinall, R.J., Ramos-Martín, J., \& Bukkens, S.G.F. (Eds.) (2014). Resource Accounting for Sustainability: The Nexus between Energy, Food, Water and Land Use. London: Routledge, $250 \mathrm{pp}$.

London, B. (1932). Ending the depression through planned obsolescence.

Lotka, A. J. (1922) Contribution to the energetics of evolution. Proceedings of the National Academy of Sciences 8, 147-151.

Madrid, C., Cabello, V., \& Giampietro, M. (2013). Water-Use Sustainability in Socioecological Systems: A Multiscale Integrated Approach. BioScience 63(1), 14-24. doi:

10.1525/bio.2013.63.1.6.

Madrid-Lopez C., J. Cadillo-Benalcazar, F. Diaz-Maurin, Z. Kovacic, T. Serrano-Tovar, T. Gomiero, M. Giampietro, R.J. Aspinall, J. Ramos-Martin, \& S.G.F. Bukkens (2014). Chapter 13. Punjab State, India. In: Giampietro, M., Aspinall, R.J., Ramos-Martín, J., \& Bukkens, S.G.F. (Eds.). Resource Accounting for Sustainability: The Nexus between Energy, Food, Water and Land Use. London: Routledge, 250 pp.

Mayumi, K., \& Giampietro, M. (2014). Proposing a general energy accounting scheme with indicators for responsible development: Beyond monism. Ecological Indicators 47, 50-66. doi:10.1016/j.ecolind.2014.06.033.

Odum, H.T. (1963). Limits of remote ecosystems containing man. The American Biology Teacher 25(6), 429-443.

Odum, H.T. (1971). Environment, Power and Society. New York: Wiley-Interscience.

Odum, H.T. (1983). Systems Ecology. New York: John Wiley.

Odum, H.T. (1994). Ecological and General Systems: An Introduction to Systems Ecology. Colorado University Press.

Odum, H.T. (1996). Environmental Accounting: Emergy and Environmental Decision Making. New York: John Wiley.

Odum, H.T., \& Pinkerton, R.C. (1955). Time's speed regulator: The optimum efficiency for maximum power output in physical and biological systems. American Scientist 43, 321-343.

Serrano-Tovar T., J. Cadillo Benalcazar, F. Diaz-Maurin, Z. Kovacic, C. Madrid, M. Giampietro, R.J. Aspinall, J. Ramos-Martin, \& S.G.F. Bukkens (2014). Chapter 12. The Republic of 
Mauritius. In: Giampietro, M., Aspinall, R.J., Ramos-Martín, J., \& Bukkens, S.G.F. (Eds.). Resource Accounting for Sustainability: The Nexus between Energy, Food, Water and Land Use. London: Routledge, $250 \mathrm{pp}$.

Smil, V. (2010). Energy Transitions: History, Requirements, Prospects. Santa Barbara, CA: Praeger, 178 pp.

Smil, V. (2015). Power Density: A Key to Understanding Energy Sources and Uses. Cambridge, MA: The MIT Press, 320 pp.

US Census Bureau (2014). America's Families and Living Arrangements: 2014: Average number of people (AVG table series). U.S. Department of Commerce, Census Bureau. http://www.census.gov/hhes/families/data/cps2014AVG.html (accessed 23.10.15)

US EIA (2009). Residential Energy Consumption Survey (RECS), 2009 RECS Survey Data, Consumption \& Expenditures (C\&E) Tables. U.S Energy Information Administration. http://www.eia.gov/consumption/residential/data/2009/index.cfm?view=consumption (accessed 23.10.15)

Zipf, G.K. (1941). National Unity and Disunity: The Nation as a Bio-Social Organism. Bloomington, IN: The Principia Press. 